\title{
Getting the Hours You Want in the Preretirement Years: Work Hour Preferences and Mismatch Among Older Canadian Workers
}

Michelle Pannor Silver, Jason Settels, Markus H Schafer, Scott Schieman

\begin{abstract}
:
Expectations regarding the work hours of older workers have changed over time. This article examines Canadian workers in their pre-retirement years to identify patterns in work hour preferences by gender - and whether work hour mismatch predicts late-stage workforce transitions. Findings from a national sample of Canadian workers show that slightly over half of all respondents were content with the number of hours they worked, but that $36 \%$ of the sample expressed a preference to work fewer hours and more than $8 \%$ expressed a preference to work more hours. Among men and women there were remarkable similarities in the factors that predicted a mismatch between respondents' preferred and actual hours worked. While highlighting heterogeneity in the work hour preferences of Canadian workers in the years leading up to traditional retirement age, findings illustrate how mismatches between workers' preferred and actual work hours predict later career workforce transitions. Findings also emphasize the importance of good relations with coworkers and supervisor support as factors that can enhance preferences to continue working at later career stages. Our findings also support claims that employers ought to be encouraged to focus on later career transitions and to find opportunities to enhance the fit between the number of hours required to meet work demands with individuals' capabilities and interests.
\end{abstract}

\section{https://doi.org/10.1093/workar/way015}

https://academic.oup.com/workar/article-abstract/5/2/175/5237921 